EXTENDED REPORT

\title{
T lymphocyte mediated lysis of mitomycin C treated Tenon's capsule fibroblasts
}

\author{
J G Crowston, L H Chang, J T Daniels, P T Khaw, A N Akbar
}

Br J Ophthalmol 2004;88:399-405. doi: 10.1136/bjo.2003.007708

See end of article for authors' affiliations .....................

Correspondence to: J G Crowston, Hamilton Glaucoma Center, UCSD, 9500 Gilman Drive, La Jolla, CA 92093-0946, USA; jcrowston@ucsd.edu

Accepted for publication 25 June 2003

\begin{abstract}
Aims: To evaluate the effect of T cell co-culture on mitomycin $C$ treated and untreated Tenon's capsule fibroblasts.

Methods: IL-2 dependent allogeneic T cells were incubated over a monolayer of mitomycin C treated or control fibroblasts. Fibroblast numbers were evaluated by direct counts using phase contrast microscopy. To determine whether T cell mediated lysis was a consequence of $\mathrm{MHC}$ mismatch, co-culture experiments were repeated with autologous $T$ cells. The effect of Fas receptor blockade was established by coincubation with a Fas blocking (M3) antibody.

Results: T cell co-culture resulted in a dramatic reduction in fibroblast survival compared to mitomycin C treatment alone $(p=0.032)$. T cell killing required fibroblast/lymphocyte cell to cell contact and was observed in both allogeneic and autologous co-culture experiments. Fas blocking antibodies did not significantly inhibit T cell killing $(p=0.39)$.

Conclusion: T cells augment mitomycin $C$ treated fibroblast death in vitro. Similar mechanisms may contribute to the cytotoxic effect of mitomycin $C$ in vivo and account for the largely hypocellular drainage blebs that are observed clinically.
\end{abstract}

ntraoperative mitomycin C use during trabeculectomy provides a potent, longstanding antifibrotic effect. We have shown previously that clinically relevant applications of mitomycin C induce apoptotic death in Tenon's capsule fibroblasts and hypothesised that this drug is effective by prematurely switching off the wound healing response. ${ }^{1}$ Indirect evidence supporting widespread fibroblast death in vivo is derived from cell culture and the histological and clinical appearance of mitomycin C treated filtration blebs. ${ }^{2-4}$ This suggests that the antifibrotic effect of mitomycin $C$ is not only derived from the inhibition of fibroblast proliferation, but is also a consequence of widespread fibroblast death.

Activated $\mathrm{T}$ cells and natural killer cells induce target cell apoptosis by ligating death receptors (Fas or the tumour necrosis factor receptor) on the target cell surface ${ }^{5}$ or by a perforin dependent mechanism. ${ }^{6}$ Perforin "punches" holes in the target cell membrane allowing entry of granzyme B into the cell to initiate apoptosis. We have shown previously that Tenon's fibroblasts constitutively express the death receptor Fas in vitro and that mitomycin C upregulates Fas expression in a dose dependent manner. ${ }^{7}$ We were therefore interested to determine whether mitomycin C also rendered Tenon's fibroblasts susceptible to $\mathrm{T}$ cell lysis. The purpose of this study was to:

(1) establish the effect of $\mathrm{T}$ cell co-culture on mitomycin $\mathrm{C}$ treated fibroblasts; and

(2) evaluate the effect of Fas receptor blockade on T cell augmented fibroblast death.

\section{METHODS}

\section{Fibroblast culture}

Human Tenon's capsule fibroblasts (HTF) were propagated from explanted subconjunctival Tenon's capsule isolated during glaucoma filtration surgery as described previously. ${ }^{8}$ The tenets of the Declaration of Helsinki were followed and institutional human experimentation committee approval was granted. Explanted tissue was anchored onto the bottom of a six well plate (Becton Dickinson, San Jose, CA, USA) with a sterile coverslip and overlaid with Dulbecco Modified Eagle's Medium (DMEM; Sigma, Poole UK). All media used were supplemented with L-glutamine $2 \mathrm{mM}$ and penicillin 100000 units/l (all Gibco, Uxbridge, UK) and fetal calf serum (FCS; 10\% of final volume; Gibco, Uxbridge, UK). Once the monolayers had reached confluence the fibroblasts were passaged and cultured in $175 \mathrm{~cm}^{2}$ tissue culture flasks.

\section{Generation of an IL-2 dependent T cells}

Peripheral blood mononuclear cells (PBMC) were separated from venous blood by density gradient cytocentrifugation as described previously. ${ }^{9}$ Approximately $40 \mathrm{ml}$ of heparinised $(10 \mathrm{U} / \mathrm{ml}$ ) peripheral venous blood was diluted $1: 2 \mathrm{in} 100 \mathrm{ml}$ Hank's buffered saline solution (Gibco) in $1000 \mathrm{ml}$ sterile water (Baxter Health Care), layered over Ficoll-Hypaque (Nycomed) and centrifuged at $1800 \mathrm{rpm}$ for 30 minutes. The interface containing mononuclear cells was gently aspirated, washed twice, and counted. The cells were then resuspended in RPMI culture medium supplemented with $10 \%$ fetal calf serum at a concentration of $1 \times 10^{6}$ cells per $\mathrm{ml}$.

To generate short term cultures of activated T cells, PBMC were activated by the addition of the lectin phytohaemagglutinin (PHA; Wellcome Ltd) at a concentration of $1 \mu \mathrm{g} / \mathrm{ml}$ in RPMI supplemented with $10 \%$ fetal calf serum for 4 days, as previously described. ${ }^{10}$ The cells were then washed and maintained in interleukin-2 (IL-2, R\&D Abingdon, UK) supplemented media at a concentration of $2 \mathrm{ng} / \mathrm{ml}$ for at least 7 days before use.

\section{Mitomycin C application and $\mathrm{T}$ cell/fibroblast co- culture}

Tenon's fibroblasts were seeded at a concentration of 20000 fibroblasts per well into 24 well plates (Becton Dickinson) and incubated overnight. The fibroblast monolayers were then washed and covered with a single applications of mitomycin C (Kyowa Hakko Kogyo Ltd) as described previously. ${ }^{2}$ Unless otherwise stated, the treatment time for all experiments was 5 minutes. Antimetabolites were diluted 
in either phosphate buffered saline (PBS, Sigma) or serum free culture medium. Control fibroblasts were treated with a 5 minute application of PBS. Following treatment the monolayers were washed immediately at least three times and incubated in RPMI (Sigma) growth medium. IL-2 dependent PHA activated T cells were added to the culture medium with an effector:target cell ratio of 20:1 as described previously. ${ }^{11}$

\section{Determination of viable fibroblast number Phase contrast microscopy}

Fibroblast number was determined from the number of attached fibroblasts per $\times 40$ field as previously described. ${ }^{12}$ This assay is based on the assumption that dead fibroblasts detach from the monolayer. Fibroblast monolayers were washed at least twice to remove co-cultured $\mathrm{T}$ cells. The monolayers were then air dried overnight and stained with Diffquik. The number of fibroblast nuclei per $\times 40$ field were counted using a phase contrast microscope (Olympus OS2). Fibroblast number is expressed as the mean number per field from five randomly selected fields per well. There were four replicate wells per treatment group.

\section{Lactate dehydrogenase (LDH) release assays}

A lactate dehydrogenase release assay was also used to quantify cell death. Lactate dehydrogenase is a stable cytoplasmic enzyme present in all cells. It is rapidly released upon damage to the plasma membrane. Lactate dehydrogenase was measured in the supernatant of Tenon's fibroblasts or Jurkat $\mathrm{T}$ cells using the cytotoxicity detection kit (LDH; Boehringer Mannheim, Philadelphia, PA, USA) according to the manufacturer's guidelines. Briefly, HTF or Jurkat T cells were incubated in $400 \mu \mathrm{l}$ phenol red-free culture medium after a given treatment for 48 hours; $100 \mu$ l of supernatant were extracted from each well and placed into separate wells of a 96 well plate (Becton Dickinson); $100 \mu \mathrm{l}$ of catalyst solution $\left(\right.$ at $\left.37^{\circ} \mathrm{C}\right)$ were added to each well and incubated for 15 minutes. Absorbance was measured with a microtitre plate reader (Titertek Plus, ICN Flow) using a 490-492 nm filter. Background absorbance was measured with wells containing phenol red-free culture medium only. Low controls were derived from supernatant of untreated cells. High controls, equating to $100 \%$ cell death were obtained by lysing untreated cells with $100 \mu \mathrm{l}$ of $0.1 \%$ Triton-X added to $300 \mu \mathrm{l}$ phenol red-free DMEM. The percentage apoptosis was calculated by the equation:

$$
\begin{aligned}
\% \text { cell death }= & (\text { experimental value }- \text { low control }) / \\
& (\text { high control }- \text { low control })
\end{aligned}
$$

As serum contains inherent LDH activity, this assay can only be used to measure cell death in serum free conditions. In addition, this assay was not used in co-culture experiments as it does not distinguish between fibroblast and lymphocyte death.

\section{Modified lactate dehydrogenase assay}

The LDH assay was modified to count viable (attached) fibroblasts. Monolayers were washed gently with PBS. Residual attached fibroblasts were lysed with $0.1 \%$ Triton-X in $300 \mu \mathrm{l}$ phenol red-free DMEM; $100 \mu \mathrm{l}$ of lysed cell supernatant were then added to $100 \mu \mathrm{l}$ of catalyst solution and absorbance was measured as described above.

\section{T cell fibroblast contact}

$\mathrm{T}$ cell fibroblast contact was inhibited in some experiments by seeding $\mathrm{T}$ cells into cell culture inserts (Becton Dickinson). These inserts incorporate membranes that are transparent and contain $0.4 \mu \mathrm{m}$ pores which allow free passage of soluble factors but are too small to permit cell migration.

\section{Identification of natural killer cells}

$\mathrm{T}$ cells were harvested from PHA activated $\mathrm{T}$ cells and maintained in IL-2 for 1-3 weeks. Cell concentrations were corrected to $1 \times 10^{6}$ per ml. Anti-CD56-FITC (natural killer cell marker) and anti-CD3-PE (pan-T cell marker) were added to $100 \mu \mathrm{l}$ of cells (final antibody concentration $5 \mu \mathrm{g} / \mathrm{ml}$ ) and incubated for 30 minutes at room temperature in the dark. The cell suspensions were washed twice with PBS, fixed in paraformaldehyde, and analysed by flow cytometry. Viable lymphocyte populations were gated from forward versus side scatter profiles and analysed for CD3 and CD56 expression. FITC and PE conjugated isotype controls were used to determine background fluorescence. Scatter plots of fluorescence intensity in FL-1 (FITC) against FL-2 (PE) were plotted and quadrants set to distinguish positive from negative staining on the basis of the fluorescence intensity of the isotype controls. $\mathrm{CD}^{-} / \mathrm{CD} 56^{+}$cells represent the natural killer cell population. The percentage of cells with this phenotype was assessed on two separate occasions in two independent $\mathrm{T}$ cell cultures.

\section{Fas blockade}

Jurkat T cells

We used a Fas sensitive Jurkat T cells (clone J6) as a positive cellular control to investigate Fas blockade. Previous experiments had demonstrated dose dependent induction of apoptosis with a Fas activating anti-Fas IgM (CHIl; Upstate Biotechnology; data not shown). Fas receptor blockade was performed using anti-Fas M3 (Immunotech) which binds to the receptor and prevents receptor activation. An IgG isotype control antibody (M33, Immunotech) binds to Fas but has no effect on signal transduction. Jurkat $\mathrm{T}$ cells were incubated in anti-Fas M3 $(10 \mu \mathrm{g} / \mathrm{ml})$ or isotype control (M33; $10 \mu \mathrm{g} / \mathrm{ml}$ ) for 30 minutes before and after addition of anti-Fas IgM (CHll; $50 \mathrm{ng} / \mathrm{ml})$. Jurkat apoptosis was evaluated using the lactate dehydrogenase release assay.

\section{T cell fibroblast co-culture}

To determine whether $\mathrm{T}$ cell induced death in mitomycin $\mathrm{C}$ treated fibroblasts results from upregulated Fas expression, fibroblasts were pre-incubated with anti-Fas (M3; $10 \mu \mathrm{g} / \mathrm{ml}$ ) for 30 minutes before mitomycin C $(0.4 \mathrm{mg} / \mathrm{ml}$ for 5 minutes or PBS in controls) treatment to block the Fas receptor, as previously described. ${ }^{13}{ }^{14}$ Allogeneic PHA activated T cells maintained in IL-2 $(2 \mathrm{ng} / \mathrm{ml})$ were added immediately after mitomycin $\mathrm{C}$ treatment together with further anti-Fas M3 at a concentration of $10 \mu \mathrm{g} / \mathrm{ml}$. Viable fibroblast number was assessed either by counting attached fibroblast numbers or with the modified lactate dehydrogenase assay.

\section{Statistical analysis}

Experiments were replicated at least twice with four replicates per treatment group. Statistical analysis was performed on the mean fibroblast number per $\times 40$ field (phase contrast microscopy) or the absorbance value ( $\mathrm{LDH}$ release and modified LDH release assays). As we were unable to demonstrate a normal distribution with $\mathrm{n}=4$, comparison of treatment groups was performed with the Mann-Whitney U using Prism (Graphpad, Chicago, IL, USA).

\section{RESULTS}

\section{T cell mediated fibroblast killing}

We evaluated viable fibroblast number after 72 hours of coculture using phase contrast microscopy. Allogeneic PHA activated $\mathrm{T}$ cell co-culture with mitomycin $\mathrm{C}$ treated fibroblasts led to a significant reduction in fibroblast number 

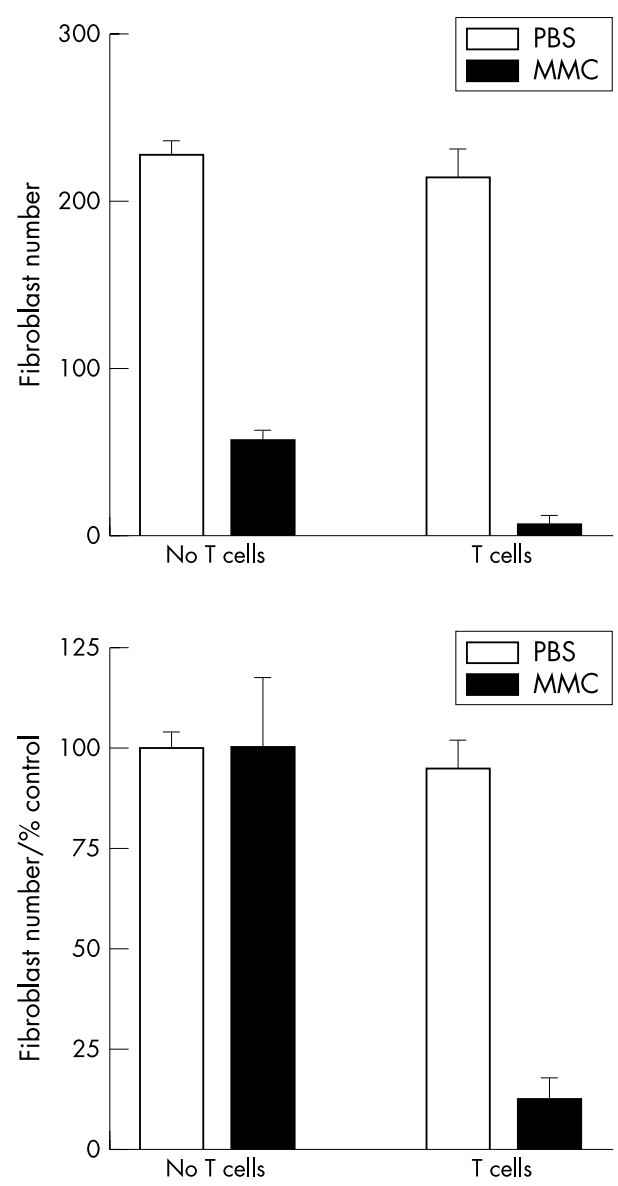

Figure 1 The effect of T cell co-culture on mitomycin C (MMC) treated Tenon's fibroblasts. Fibroblasts were treated for 5 minutes with mitomycin C $0.4 \mathrm{mg} / \mathrm{ml}$ or PBS and incubated with or without PHA activated T cells (effector:target cell ratio $=20: 1$ ). Attached fibroblasts were counted with phase contrast microscopy after 72 hours and expressed as mean fibroblast number per field (top) and as a percentage of non-co-cultured fibroblast number to cancel the direct effect of mitomycin $\mathrm{C}$ on fibroblast number (bottom). T cell co-culture led to a significant reduction in viable fibroblasts compared to mitomycin $C$ treatment alone $(p=0.032)$. Co-culture had little effect on PBS treated fibroblast number. These data represent mean values (SEM) for three independent experiments.

compared to mitomycin $\mathrm{C}$ in the absence of $\mathrm{T}$ cell co-culture $(p=0.032$; fig $\mathrm{l}$, Mann-Whitney $\mathrm{U}$, comparison of mean fibroblast number per field from three independent experiments with $\mathrm{n}=4$ for each treatment group). Small numbers of apoptotic fibroblasts were seen in some experiments in the PBS treated control fibroblasts. The reduction in co-cultured PBS treated fibroblast number was small and did not reach statistical significance. The data are expressed graphically as absolute fibroblast number and also as a percentage value where the non-co-cultured fibroblast number is corrected to represent $100 \%$ (fig 1). This negates the reduction in fibroblast number as a result of the direct effects of mitomycin C.

\section{Fibroblast/T cell contact}

Cell culture inserts which contain $0.4 \mu \mathrm{m}$ pores allow free passage of soluble factors but prevent cell migration and therefore T cell/fibroblast contact. T cells placed in cell culture inserts were co-cultured with mitomycin $\mathrm{C}$ treated fibroblasts. Fibroblast number was determined by counting attached fibroblasts with phase contrast microscopy. This experiment was performed on two separate occasions. In both experiments, $\mathrm{T}$ cell co-culture led to a significant reduction in fibroblast number compared to mitomycin $\mathrm{C}$ treatment alone $(\mathrm{p}<0.01, \mathrm{p}=0.029)$. However, $\mathrm{T}$ cell killing was completely blocked when fibroblast/T cell contact was prevented and there was no significant reduction in fibroblast number compared to mitomycin $\mathrm{C}$ treatment and no $\mathrm{T}$ cell coculture $(p=0.34$ and $p=0.12$ Mann-Whitney $U$; fig 2).

\section{Characterisation of $\mathrm{T}$ cells}

PHA activated IL-2 dependent T cells were maintained in IL-2 ( $2 \mathrm{ng} / \mathrm{ml}$ ) for 1 week before use in experiments as previously described. ${ }^{15}$ Natural killer cells can also be propagated under these conditions and therefore potentially contaminate the $\mathrm{T}$ cells. To determine the relative numbers of T lymphocyte and natural killer cells, we investigated CD3 and CD56 expression after 1 and 3 weeks of culture in IL-2. This revealed that approximately $90 \%$ of cells were T lymphocytes $\left(\mathrm{CD}^{+}\right)$and below 5\% were natural killer cells $\left(\mathrm{CD}^{-} / \mathrm{CD}^{2} 6^{+}\right.$; fig 3$)$. Further characterisation for CD4/CD8 expression revealed approximately $75 \%$ expressed CD8 and $25 \%$ were CD4 positive.

\section{MHC mismatch}

To exclude the possibility that $\mathrm{T}$ cell induced fibroblast death was as a consequence of MHC mismatch in these allogeneic T cell/fibroblast combinations, we planned to repeat the experiments with autologous co-cultures. However, because of logistic constraints we were unable to obtain Tenon's fibroblasts and $\mathrm{T}$ cells from the same patients. We were, however, able to obtain skin fibroblasts derived from full thickness skin biopsies from a healthy volunteer in the laboratory. We demonstrated that mitomycin C also upregulated Fas expression in skin fibroblasts (data not shown). Autologous T cell co-culture led to a significant reduction in viable mitomycin $\mathrm{C}$ treated skin fibroblast number compared to mitomycin $\mathrm{C}$ treatment alone $(\mathrm{p}<0.01$ for two independent experiments, Mann-Whitney U; fig 4, top).

\section{CD8 mediated killing}

To confirm that fibroblast death is mediated by $\mathrm{CD} 8^{+} \mathrm{T}$ cells we obtained an anti-CD3 activated allogeneic CD8 enriched $\mathrm{T}$ cells $\left(>95 \% \mathrm{CD}^{+} / \mathrm{CD}^{+}, 100 \% \mathrm{CDl6}^{-}\right)$. These lines were obtained by negative selection of anti-CD3 activated peripheral blood mononuclear cells. The antibodies used for

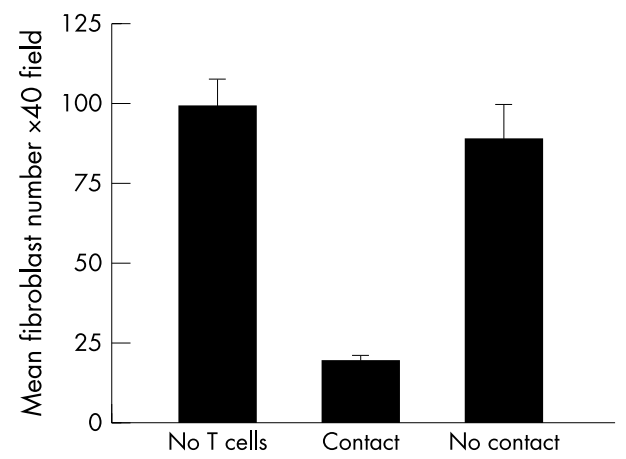

Figure 2 T cell fibroblast contact is necessary for lymphocyte mediated fibroblast death. Mitomycin C treated fibroblasts $(0.4 \mathrm{mg} / \mathrm{ml})$ were incubated alone (no T cells) or co-cultured with T cells $(E: T=20: 1)$. T cell/ fibroblast contact was permitted in one co-culture group but inhibited in the other by cell culture inserts. T cell co-culture induced a significant reduction in fibroblast number only when contact was permitted $(p=0.029)$. There was no significant change in fibroblast number when cell contact was inhibited $(p=0.12)$. The data show means (SD) derived from a representative of two separate experiments performed in quadruplicate. 

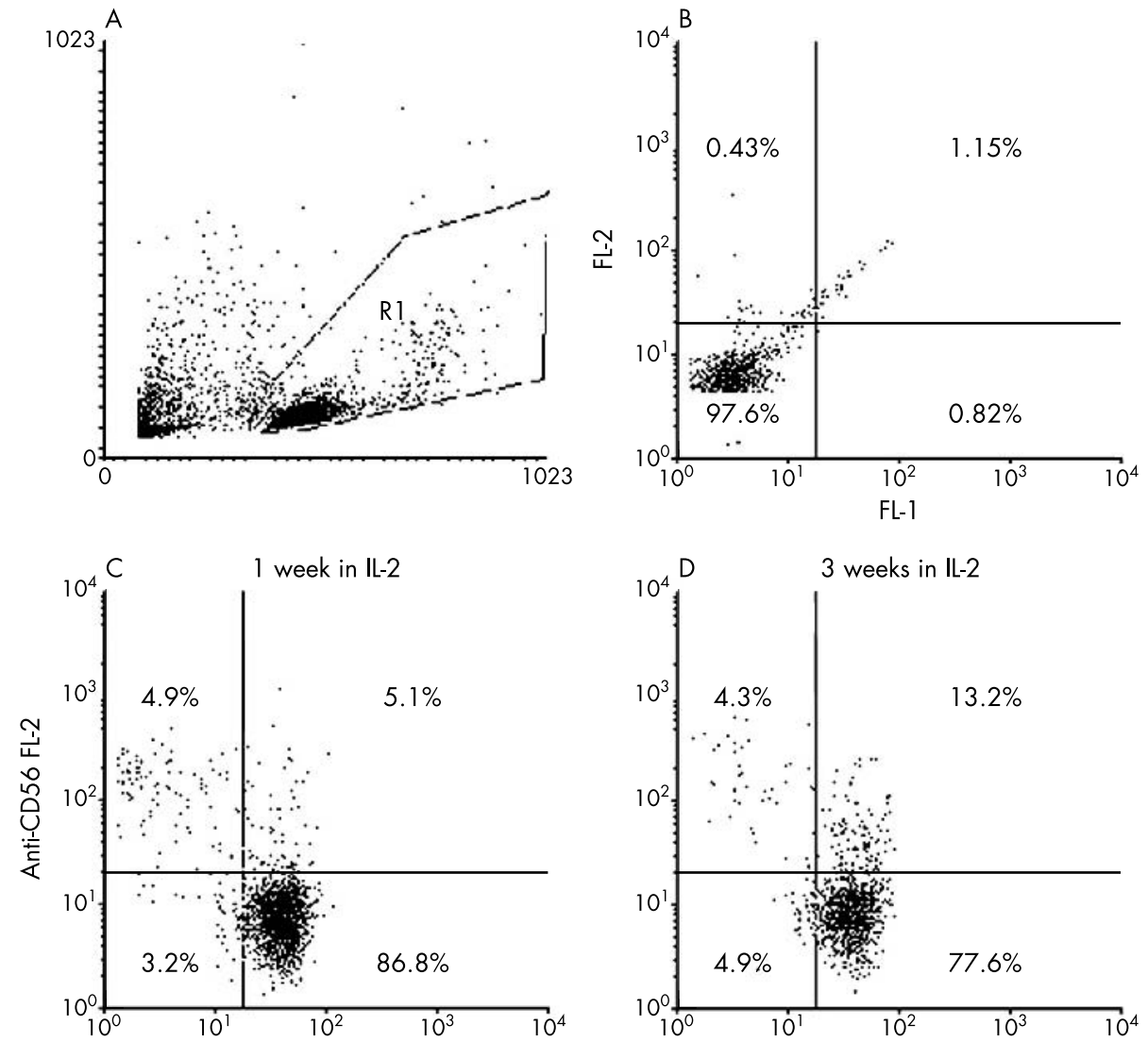

Anti-CD3/FL-1

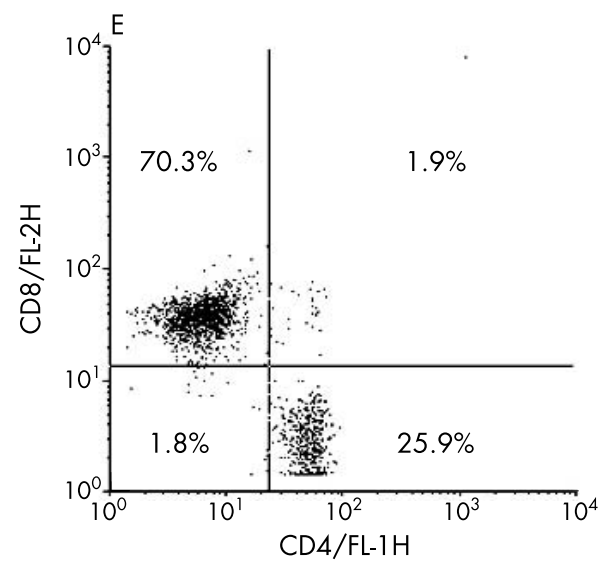

negative selection with magnetic beads were raised against CD4, CD14, CD16, and CD19 to provide a purified CD8 ${ }^{+}$ population. $\mathrm{CD}^{+}$lymphocyte co-culture with mitomycin $\mathrm{C}$ treated fibroblasts led to a significant reduction in viable fibroblast number compared to mitomycin $\mathrm{C}$ treatment alone ( $p=0.02$, Mann-Whitney $\mathrm{U}$; fig 4, bottom). Fibroblast number was assessed at 48 hours by counting attached fibroblasts by phase contrast microscopy. CD8 coculturedid not reduce PBS treated fibroblast number $(\mathrm{p}=0.17)$.

\section{Fas blockade}

\section{Jurkat T cells}

The efficacy of the Fas blocking IgG (M3) antibody was evaluated by inhibiting anti-Fas IgM (CHIl) induced apoptosis in Jurkat $\mathrm{T}$ cells using the LDH release assay. Fas
Figure 3 CD56/CD3 expression in PHA activated T cells.

Phytohaemagglutinin activated peripheral blood mononuclear cells were maintained in IL-2 $(2 \mathrm{ng} / \mathrm{ml})$. After 1 and 3 weeks in IL-2, the T cells were labelled with FITC conjugated anti-CD3 (FL-1) and PE conjugated antiCD56 (FL-2). Region R1 was used to gate viable lymphocytes (A). (B) FL-1 plotted against FL-2 for isotype control antibodies. (C) and (D) CD3 (FL-1) plotted against CD56 (FL2) for T cells maintained for 1 and 3 weeks in IL-2. Natural killer cells (CD3-/CD56+) lie in the upper left quadrant and the mean percentages are shown. The plots and percentages shown are representative values derived from two T cell lines. Three separate aliquots from each line containing 200000 cells were labelled independently. (E) The CD4:CD8 distribution at 1 week. blocking anti-Fas (M3) inhibited apoptosis ( $p<0.01$, MannWhitney U) whereas the isotype control (M33) that binds to Fas but does not inhibit Fas signalling had no effect on antiFas IgM induced apoptosis (fig 5, top).

\section{T cell fibroblast co-culture}

To determine whether $\mathrm{T}$ cell induced death in mitomycin $\mathrm{C}$ treated fibroblasts is a Fas dependent process, fibroblasts were pre-incubated with the blocking anti-Fas M3 for 30 minutes before mitomycin C treatment. Allogeneic PHA activated $\mathrm{T}$ cells maintained in IL-2 (2 ng/ml) were added immediately after mitomycin $\mathrm{C}$ together with further anti-Fas M3 at a concentration of $10 \mu \mathrm{g} / \mathrm{ml}$. Viable fibroblast number was assessed after 48 hours by counting attached fibroblast numbers or with the modified lactate dehydrogenase assay. In three separate experiments, anti-Fas 

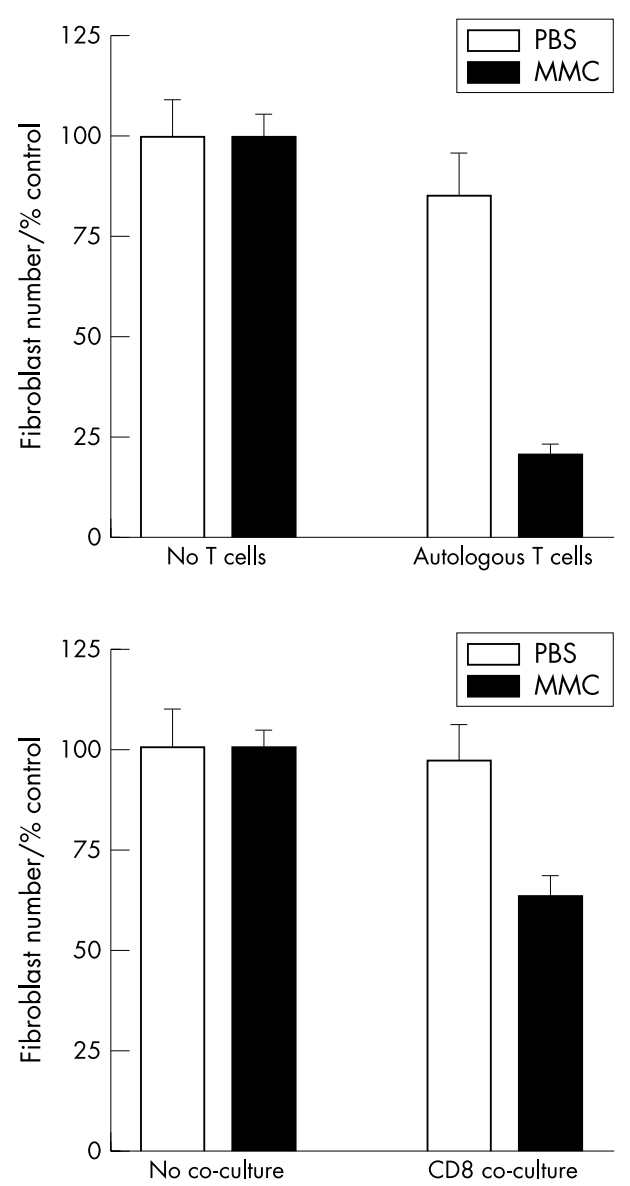

Figure 4 (Top) The effect of autologous T cell co-culture on skin fibroblast survival. Skin fibroblasts were treated with mitomycin $\mathrm{C}$ or PBS. Autologous PHA activated T cells were added immediately after treatment. Viable fibroblast number was assessed after 48 hours by phase contrast microscopy and is expressed as a percentage of the control fibroblast number (No T cells). T cell co-culture led to a significant reduction in $M M C$ treated fibroblast number $(p<0.01$ for two independent experiments performed in quadruplicate). The data shown are a representative of two separate experiments performed in quadruplicate. (Bottom) The effect of allogeneic $\mathrm{CD}^{+}{ }^{+}$purified T cells on Tenon's fibroblast survival. Tenon's fibroblasts were treated with mitomycin C or PBS and co-cultured with an anti-CD3 activated CD8 ${ }^{+}$ purified line for 48 hours. Viable fibroblast number was assessed at 48 hours by phase contrast microscopy and is expressed as a percentage of control fibroblast number (no T cells). CD8 co-culture led to a significant reduction in fibroblast number compared to mitomycin $C$ treatment alone $(p=0.02)$ for two independent experiments performed in quadruplicate.

M3 did not inhibit T cell mediated killing ( $\mathrm{p}>0.39$ ) compared to the non-blocking isotype control antibody (M33; fig 5, bottom).

\section{DISCUSSION}

$\mathrm{T}$ cell fibroblast interactions have a role in a number of physiological as well as pathological states, including the regulation of wound healing. ${ }^{16}$ Each cell type appears capable of either upregulating or downregulating each other's activities and these processes may be important at different stages of the wound healing response. ${ }^{18}$ The data that we have presented suggest that activated $\mathrm{T}$ cells augment mitomycin $\mathrm{C}$ mediated fibroblast killing in vitro. It is therefore possible that cytotoxic $\mathrm{T}$ cells may contribute to the antiscarring activity of mitomycin $\mathrm{C}$ and the generation of hypocellular drainage blebs.
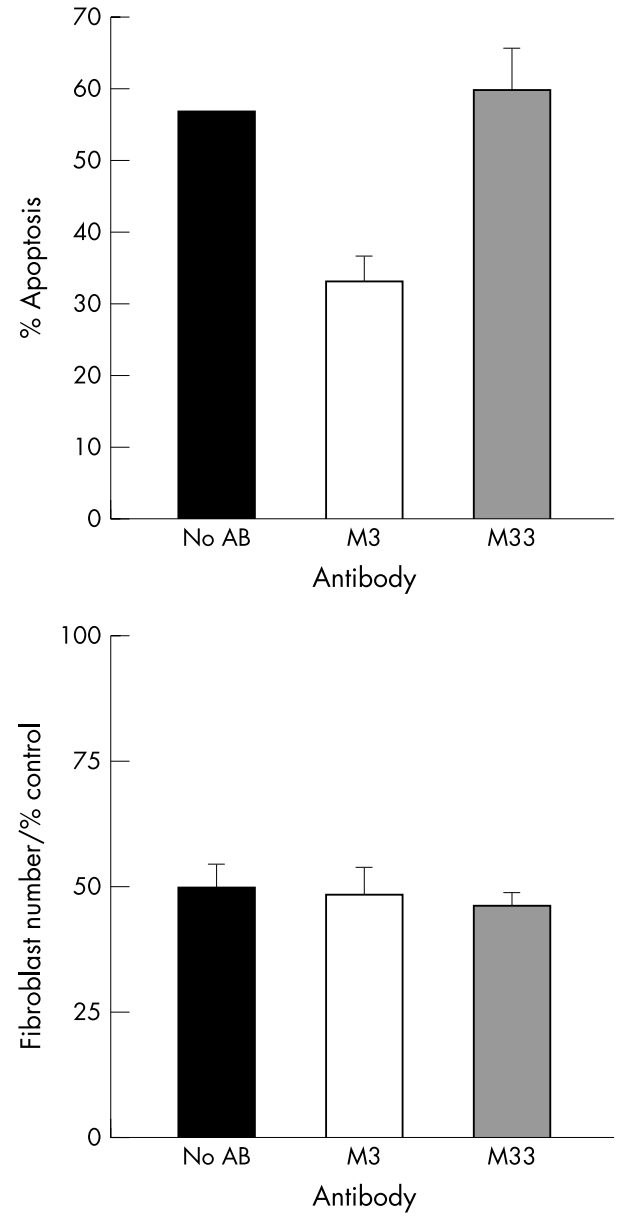

Figure 5 (Top) The effect of Fas blocking (M3) antibody on Fas induced Jurkat T cell apoptosis. Jurkat T cells were incubated in $10 \mathrm{mg} / \mathrm{ml}$ antiFas M3 for 30 minutes before the addition of $100 \mathrm{ng} / \mathrm{ml}$ of anti-Fas $\operatorname{lgM}$. Apoptosis was measured with the lactate dehydrogenase release assay. Anti-Fas M3 significantly inhibits anti-Fas IgM induced apoptosis $(p<0.01)$. An isotype control antibody (M33) did not inhibit Fas induced apoptosis. The data shown are representative data from two separate experiments performed in quadruplicate. (Bottom) The effect of Fas blocking M3 antibody on T cell / fibroblast co-culture. Tenon's fibroblasts were pre-incubated with no antibody, M3 or $M 33(10 \mathrm{mg} / \mathrm{ml})$ for 30 minutes then treated with mitomycin C $(0.4 \mathrm{mg} / \mathrm{ml}$ for 5 minutes). PHA activated $T$ cells were then added $(E: T=20: 1)$. Viable fibroblast number was counted at 48 hours with the modified LDH release assay. M3 had little effect on T cell mediated killing. Values were shown as a percentage of the control fibroblast number. The data shown are representative of three separate experiments performed in quadruplicate.

We have previously demonstrated elevated Fas expression in mitomycin $\mathrm{C}$ treated Tenon's fibroblasts and postulated that this may render mitomycin $\mathrm{C}$ damaged fibroblasts susceptible to cytotoxic $\mathrm{T}$ cell killing. Allogeneic $\mathrm{T}$ cell coculture with mitomycin $\mathrm{C}$ treated fibroblasts dramatically reduced fibroblast survival compared to mitomycin $\mathrm{C}$ treatment alone. Low levels of fibroblast death were also occasionally seen in non-treated fibroblasts; particularly in experiments utilising recently activated $\mathrm{T}$ cells. This may reflect the fact that Tenon's fibroblasts express low levels of the Fas receptor constitutively in vitro. ${ }^{7}$ The lactate dehydrogense assay used in our experiments gives a measure of the amount of cell death. It does not differentiate apoptosis from necrosis. We are therefore not able to conclude whether fibroblast death in this system is largely the result of apoptosis or necrosis but it is possible that both modes of cell death are present. ${ }^{19}$ 
We investigated the role of the death receptor Fas in $\mathrm{T}$ cell cytotoxicity, as we have previously shown this receptor to be upregulated in Tenon's fibroblasts following exposure to mitomycin C. Fas receptor blockade, however, had minimal effect on $\mathrm{T}$ cell killing. These findings are in contrast with a previous study which demonstrated that Fas receptor blockade, with similar blocking antibodies to that used in this study, inhibited $\mathrm{T}$ cell killing of human colon carcinoma cells which had been primed by a variety of chemotherapeutic agents including mitomycin C. ${ }^{14}$ If Fas signalling does not contribute to T cell mediated apoptosis in Tenon's fibroblasts, why are mitomycin C treated cells more susceptible to T cell killing? Firstly, persistent killing may be a consequence of alternative killing mechanisms which prevail when the Fas pathway is blocked. Perforin induced target cell death is well established ${ }^{20}$ and other less established mechanisms ${ }^{21}$ may take over when the Fas system is rendered non-functional. Alternative possibilities include upregulated MHC class I expression or an increase in the expression of LFA-3 and ICAM. These adhesion molecules are expressed in fibroblasts and permit $\mathrm{T}$ cell/fibroblast adhesion. ${ }^{21}$ Recent evidence has shown that cytotoxic agents including 5-fluorouracil upregulated ICAM (and Fas) in human colon cancer cells rendering treated cells susceptible to T cell lysis. ${ }^{22}$ Further investigation is necessary to determine the processes that modulate the susceptibility of mitomycin $\mathrm{C}$ treated fibroblasts to $\mathrm{T}$ cell mediated killing in vitro. It is feasible that a large number of cell surface proteins are upregulated in response to genotoxic damage. These proteins may alert the immune system to the presence of a DNA damaged cell and facilitate its clearance by the immune system. Such changes help to ensure that potentially malignant cells, which themselves may fail to undergo apoptosis, are eliminated.

The techniques used to generate our IL-2 dependent T cells also promote activation and proliferation of natural killer cells, which may contribute to fibroblast killing. To exclude the possibility of significant natural killer cell involvement in our experiments, we investigated the relative number of $\mathrm{T}$ cells and natural killer cells. The natural killer cell population was less than $5 \%$ over the time frame used in our experiments. Furthermore fibroblast killing was also demonstrated in a CD8 enriched $\mathrm{T}$ cells $\left(>95 \% \mathrm{CD}^{+} / \mathrm{CD}^{+}, 100 \%\right.$ $\mathrm{CD}^{-} 6^{-}$) which contained no natural killer cells. An additional finding from this experiment was that the mode of $\mathrm{T}$ cell activation does not appear to be important, as non-antigen (PHA) as well as antigen specific (anti-CD3) activation of lymphocytes led to preferential killing of mitomycin $\mathrm{C}$ treated fibroblasts. Finally, T cell mediated killing was not a consequence of the MHC mismatch inherent in the allogeneic set-up used for these experiments as we demonstrated similar killing in experiments co-culturing autologous skin fibroblasts with PHA activated fibroblasts derived from the same person.

Postoperative bleb inflammation is associated with scar formation in clinical practice. The findings outlined above appear to contradict this with the notion that activated $\mathrm{T}$ cells may assist in the elimination of fibroblasts and augment the effect of mitomycin $\mathrm{C}$ in downregulating the scarring process. Barbul et al have previously postulated that lymphocytes may have a dual role by initially driving and ultimately suppressing the wound healing response. ${ }^{18}$ Our experiments examined only the effect of a predominantly CD8+ cytotoxic population of $\mathrm{T}$ cells on fibroblast co-culture. The profile of inflammatory cells in drainage blebs in vivo is largely unknown but is likely to contain a variety of lymphocyte subtypes as well as neutrophils and macrophages; all of which may participate in regulating scar formation. Cytotoxic $\mathrm{T}$ cell activity in the context of these experiments reflects their potential role in eliminating DNA damaged (mitomycin C treated) fibroblasts. Further insight into the role of inflammatory cells in postoperative bleb tissue is necessary to understand the varied response of different patient groups to surgery, the mechanism of action of existing treatment strategies, as well as providing alternative methods for controlling scar formation after trabeculectomy.

\section{ACKNOWLEDGEMENTS}

This work was funded by the Wellcome Trust: grants 045202 (JGC), 1055183 (LHC); Keeler Scholarship (RCOphth; JGC), and the RNIB (JTD).

This work was undertaken by the authors who receive support from the NHS Executive. The views expressed in the publication are those of the authors and not necessarily the NHS Executive.

\section{Authors' affiliations}

J G Crowston, L H Chang, J T Daniels, P T Khaw, Wound Healing Research Unit, Institute of Ophthalmology, Bath Street, London ECIV 9EL, UK

J G Crowston, L H Chang, P T Khaw, Glaucoma Unit, Moorfields Eye Hospital, City Road, London ECIV 2PD, UK

J G Crowston, L H Chang, A N Akbar, Department of Clinical Immunology, Royal Free Hospital School of Medicine, Pond Street, London NW3, UK

\section{REFERENCES}

1 Crowston JG, Akbar AN, Constable PH, et al. Antimetabolite-induced apoptosis in Tenon's capsule fibroblasts. Invest Ophthalmol Vis Sci 1998;39:449-54

2 Khaw PT, Sherwood MB, MacKay SL, et al. Five-minute treatments with fluorouracil, floxuridine, and mitomycin have long-term effects on human Tenon's capsule fibroblasts. Arch Ophthalmol 1992;110:1150-4.

3 Mietz H, Arnold G, Kirchhof B, et al. Histopathology of episcleral fibrosis after trabeculectomy with and without mitomycin C. Graefes Arch Clin Exp Ophthalmol 1996;234:364-8.

4 Shields MB, Scroggs MW, Sloop CM, et al. Clinical and histopathologic observations concerning hypotony after trabeculectomy with adjunctive mitomycin C. Am J Ophthalmol 1993;116:673-83.

5 Stalder T, Hahn S, Erb P. Fas antigen is the major target molecule for CD4+ T cell-mediated cytotoxicity. J Immunol 1994;152:1127-33.

6 Young JD, Leong LG, Liu CC, et al. Extracellular release of lymphocyte cytolytic pore-forming protein (perforin) after ionophore stimulation. Proc Natl Acad Sci USA 1986;83:5668-72.

7 Crowston JG, Chang LH, Constable PH, et al. Apoptosis gene expression and death receptor signaling in mitomycin-C-treated human Tenon capsule fibroblasts. Invest Ophthalmol Vis Sci 2002;43:692-9.

8 Khaw PT, Ward S, Porter A, et al. The long-term effects of 5-fluorouracil and sodium butyrate on human Tenon's fibroblasts. Invest Ophthalmol Vis Sci 1992:33:2043-52.

9 Akbar AN, Terry L, Timms A, et al. Loss of CD45R and gain of UCHL1 reactivity is a feature of primed T cells. $J$ Immunol 1988; 140:2171-8

10 Akbar AN, Borthwick N, Salmon M, et al. The significance of low bcl-2 expression by CD45RO T cells in normal individuals and patients with acute viral infections. The role of apoptosis in T cell memory. J Exp Med 1993;178:427-38

11 Gombert W, Borthwick NJ, Wallace DL, et al. Fibroblasts prevent apoptosis of IL-2-deprived T cells without inducing proliferation: a selective effect on Bcl-XL expression. Immunology 1996;89:397-404.

12 Constable PH, Crowston JG, Occleston NL, et al. Long term growth arrest of human Tenon's fibroblasts following single applications of beta radiation. Br J Ophthalmol 1998:82:448-52.

13 Muller M, Strand S, Hug H, et al. Drug-induced apoptosis in hepatoma cells is mediated by the CD95 (APO-1/Fas) receptor/ligand system and involves activation of wild-type p53. J Clin Invest 1997;99:403-13.

14 Micheau O, Solary E, Hammann A, et al. Sensitization of cancer cells treated with cytotoxic drugs to fas-mediated cytotoxicity. J Natl Cancer Inst 1997;89:783-9.

15 Hyde H, Borthwick NJ, Janossy G, et al. Upregulation of intracellular glutathione by fibroblast-derived factor(s): Enhanced survival of activated $\mathrm{T}$ cells in the presence of low Bcl-2. Blood 1997:89:2453-60.

16 Crowston JG, Salmon M, Khaw PT, et al. T-lymphocyte-fibroblast interactions. Biochemical Society transactions 1997;25:529-31.

17 Chang L, Crowston JG, Cordeiro MF, et al. The role of the immune system in conjunctival wound healing after glaucoma surgery. Surv Ophthalmol 2000;45:49-68. 
18 Barbul A, Shawe T, Rotter SM, et al. Wound healing in nude mice: a study on the regulatory role of lymphocytes in fibroplasia. Surgery 1989;105:764-9.

19 Oshimi Y, Oda S, Honda Y, et al. Involvement of fas-ligand and fas-mediated pathways in the cytotoxicity of human natural killer cells. J Immunol 1996; 157:2909-15.

20 Lowin B, Krahenbuhl O, Muller C, et al. Perforin and its role in T lymphocytemediated cytolysis. Experientia 1992;48:911-20.
21 Grundy JE, Pahal GS, Akbar AN. Increased adherence of CD2 peripheral blood lymphocytes to cytomegalovirus-infected fibroblasts is blocked by anti-LFA-3 antibody. Immunology 1993;78:413-20.

22 Bergmann-Leitner ES, Abrams SI. Treatment of human colon carcinoma cell lines with anti-neoplastic agents enhances their lytic sensitivity to antigenspecific CD8+ cytotoxic T lymphocytes. Cancer Immunol Immunother 2001;50:445-55. 